\title{
Model of prefabricated concrete frame in the condition of southern Vietnam
}

\author{
Hong Quan Tran ${ }^{1}$, Thanh Quang Khai Lam ${ }^{1, *}$, and Thi My Dung Do ${ }^{1}$ \\ ${ }^{1}$ Mien Tay Construction University, 20B Pho Co Dieu street, ward 3, Vinh Long city, Vinh Long \\ province, Vietnam
}

\begin{abstract}
In recent years in Vietnam, the structure of multi-storey buildings has been strongly developed in both quantity and quality, especially multi-storey buildings made from prefabricated reinforced concrete structures. Collecting documents shows that the Mekong Delta of southern Vietnam has built many multi-storey buildings using prefabricated reinforced concrete frame systems. In the southern climatic conditions, these multi-story buildings are directly affected by climate change, especially the seasonal wind load and the intensity of the wind is getting stronger and more complex, so the the work at the nodes of the frame will be affected. In this study, the authors studied the displacement of the frame system by horizontal displacement, vertical displacement, moment, shear and axial force of the frame according to three models: rigid linked frame, joint linked frame and semi-rigid linked frame.
\end{abstract}

\section{Introduction}

Over the years, multi-storey frame structure has been interested in both domestic and foreign research. The linkage model at the nodes of the frame was also studied by many authors as: used semi-rigid frams by different connection models [1-2], optimal design of frame structures with semi-rigid joints [3-4], loads affect the frame joints [5-6], influence of the semi-rigid bolted steel joints on the frame [7-11], multi-Storey concrete frame structures, effect of parameters on concrete structure [12-14], quality of concrete [15-16]...

The Mekong Delta has a sub-equatorial climate, hot and humid, heavy rain, average temperature $27^{\circ} \mathrm{C}$. In recent years, the Mekong Delta is directly affected by climate change, invasion of sea water, the influence of wind with increasing intensity. This study considers wind load factor according to Vietnamese standard TCVN2737-1995, works in the Mekong Delta of region IIA with $\mathrm{W}_{0}=83 \mathrm{kG} / \mathrm{m}^{2}$ according to the wind pressure zoning table and load combo cases in Vietnam.

\footnotetext{
*Corresponding author: lamthanhquangkhai@gmail.com
} 


\section{Materials and Methods}

\subsection{Parameters of multi-storey building model}

The surveyed building was a social housing in Vinh Long province of southern Vietnam with the following calculated data:

1. Length of beam is $6.6 \mathrm{~m}$, height is 9 floors, each floor is $3.3 \mathrm{~m}$ high

2. $30 \times 60 \mathrm{~cm}$ beam section, $70 \times 70 \mathrm{~cm}$ column section for the 5 lower floors, $50 \times 50 \mathrm{~cm}$ for the remaining upper floors.

3. The floor is $14 \mathrm{~cm}$ thick, hard wall is placed between the building and the thickness of $25 \mathrm{~cm}$.

4. Reinforced concrete frame with B22.5

5. Deadload distributed on the floor due to the weight itself (Sap2000 calculated), the layers on the floor $100 \mathrm{kG} / \mathrm{m}^{2}$, walls on beams $1000 \mathrm{kG} / \mathrm{m}$, liveload $600 \mathrm{kG} / \mathrm{m}^{2}$.

6. Windload by 2 directions: $\mathrm{W}_{0}=83 \mathrm{kG} / \mathrm{m}^{2}\left(\mathrm{~W}_{0}\right.$ : wind pressure by region)

Table 1. The front wind by levels

\begin{tabular}{|c|c|c|c|c|c|c|}
\hline Level & $\mathbf{W}_{\mathbf{0}}$ & $\mathbf{H}(\mathbf{m})$ & $\mathbf{h}_{\mathbf{t t}}(\mathbf{m})$ & $\mathbf{K}$ & $\mathbf{C}_{\mathbf{k}}$ & $\mathbf{W}_{\mathbf{K}}$ \\
\hline 9 & 83 & +29.7 & 3.3 & 1.382 & 0.8 & 91.765 \\
\hline 8 & 83 & +26.4 & 3.3 & 1.354 & 0.8 & 89.906 \\
\hline 7 & 83 & +23.1 & 3.3 & 1.330 & 0.8 & 88.312 \\
\hline 6 & 83 & +19.8 & 3.3 & 1.298 & 0.8 & 86.187 \\
\hline 5 & 83 & +16.5 & 3.3 & 1.270 & 0.8 & 84.328 \\
\hline 4 & 83 & +13.2 & 3.3 & 1.238 & 0.8 & 82.203 \\
\hline 3 & 83 & +9.9 & 3.3 & 1.158 & 0.8 & 76.891 \\
\hline 2 & 83 & +6.6 & 3.3 & 1.098 & 0.8 & 72.907 \\
\hline 1 & 83 & +3.3 & 3.3 & 1.035 & 0.8 & 68.724 \\
\hline
\end{tabular}

Table 2. The behind wind by levels

\begin{tabular}{|c|c|c|c|c|c|c|}
\hline Level & $\mathbf{W}_{\mathbf{0}}$ & $\mathbf{H}(\mathbf{m})$ & $\mathbf{h}_{\mathbf{t t}}(\mathbf{m})$ & $\mathbf{K}$ & $\mathbf{C}_{\mathbf{k}}$ & $\mathbf{W}_{\mathbf{K}}$ \\
\hline 9 & 83 & +29.7 & 3.3 & 1.382 & -0.6 & -68.824 \\
\hline 8 & 83 & +26.4 & 3.3 & 1.354 & -0.6 & -67.429 \\
\hline 7 & 83 & +23.1 & 3.3 & 1.330 & -0.6 & -66.234 \\
\hline 6 & 83 & +19.8 & 3.3 & 1.298 & -0.6 & -64.640 \\
\hline 5 & 83 & +16.5 & 3.3 & 1.270 & -0.6 & -63.246 \\
\hline 4 & 83 & +13.2 & 3.3 & 1.238 & -0.6 & -61.652 \\
\hline 3 & 83 & +9.9 & 3.3 & 1.158 & -0.6 & -57.668 \\
\hline 2 & 83 & +6.6 & 3.3 & 1.098 & -0.6 & -54.680 \\
\hline 1 & 83 & +3.3 & 3.3 & 1.035 & -0.6 & -51.543 \\
\hline
\end{tabular}

Combo:

1. Comb1: Deadload + liveload

2. Comb2: Deadload + WindloadX

3. Comb3: Deadload - WindloadX

4. Comb4: Deadload + WindloadY

5. Comb5: Deadload - WindloadY

6. Comb6: Deadload +0.9 liveload +0.9 windloadX

7. Comb7: Deadload +0.9 liveload -0.9 windloadX

8. Comb8: Deadload +0.9 liveload +0.9 windloadY

9. Comb9: Deadload +0.9 liveload -0.9 windloadY

10. BAO: (Comb1 $\div$ Comb9) 

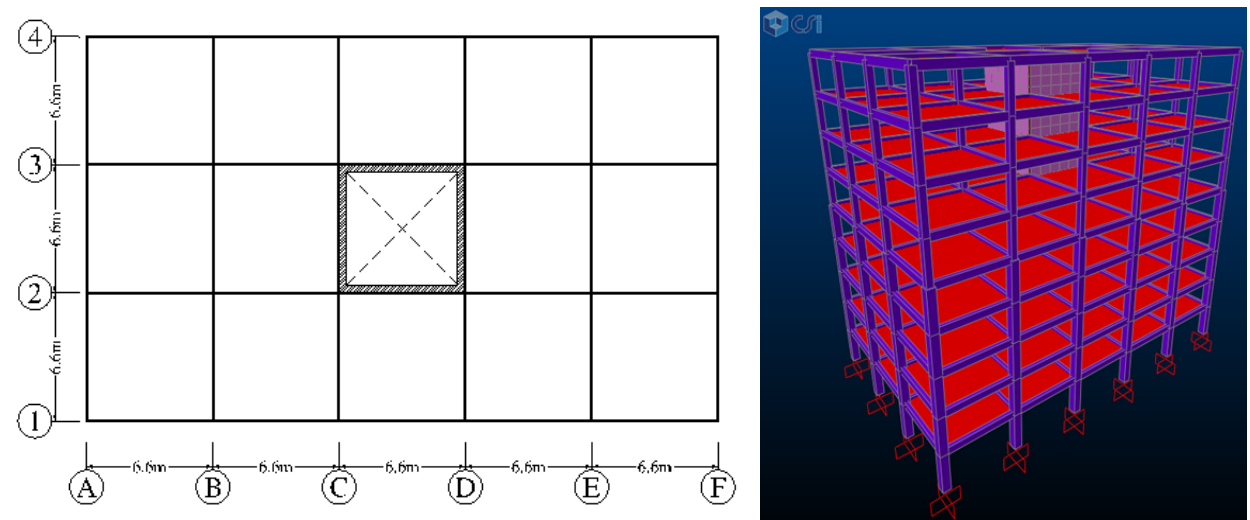

Fig 1. Ground and multi-storey building space frame model

\subsection{Element and linked models}

Using Sap2000 V10 software to calculate the internal force and displacement of the frame according to the linked diagram: rigid linked frame, joint linked frame and semi-rigid linked frame.

According to Vietnamese standards, the foot of columns are rigid link, rigid wall at center of building. At the nodes connecting the beam and the column is rigid link (see Fig2). The nodes connecting the beam and the column is joint link (see Fig 3). The joints and elements diagram for the case of semi-rigid frame, corresponds to $25 \%$ of the moment under the beam span (see Fig 4).

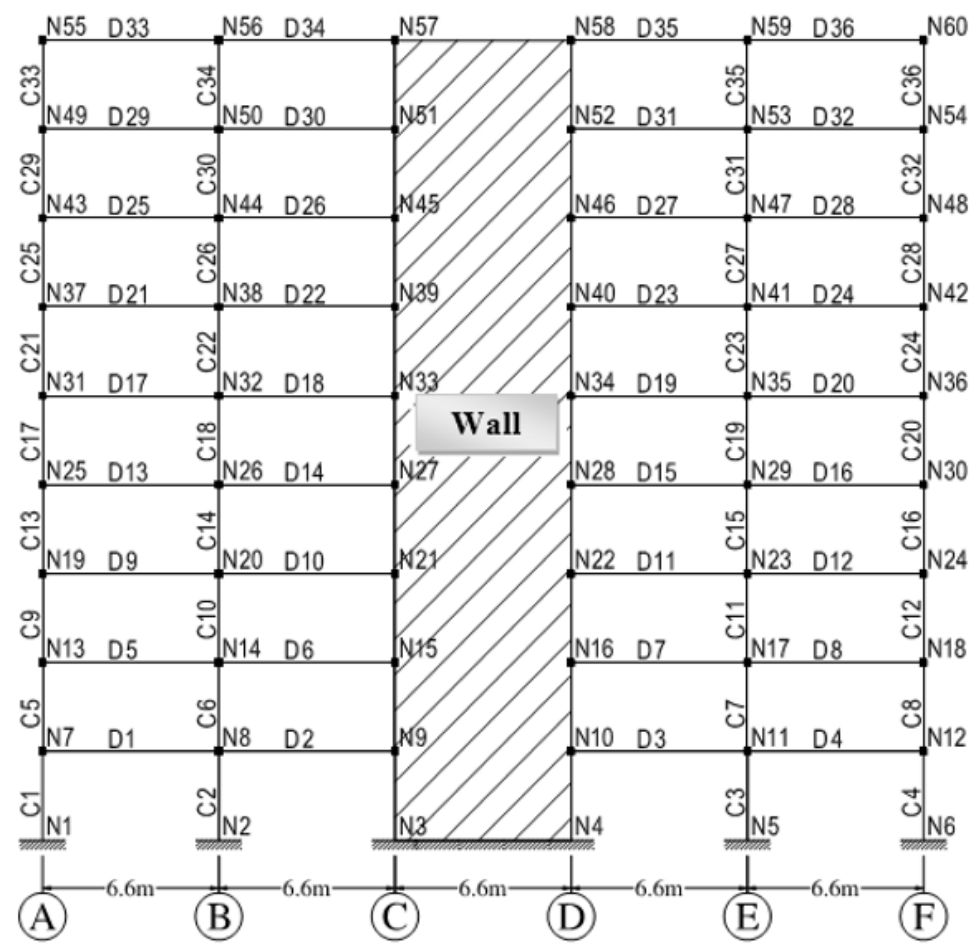

Fig 2. Node elements and rigid linked frame 


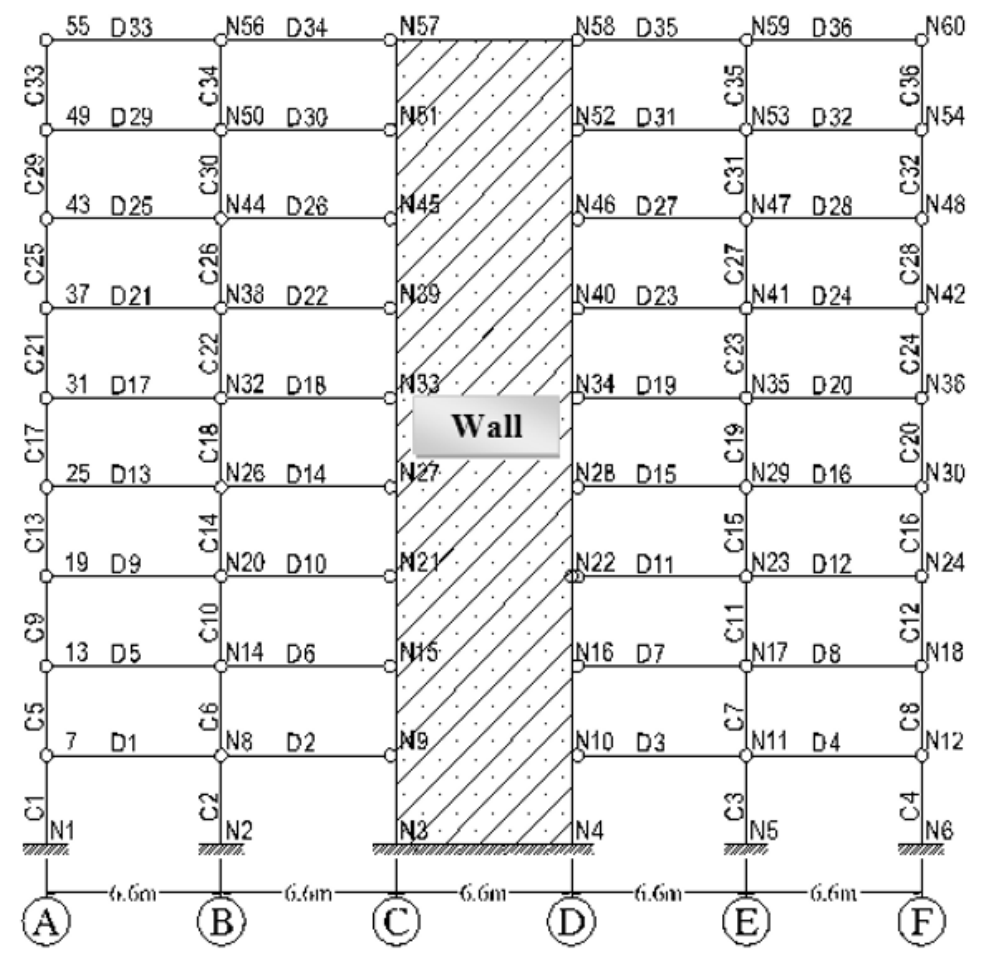

Fig 3. Node elements and joint linked frame

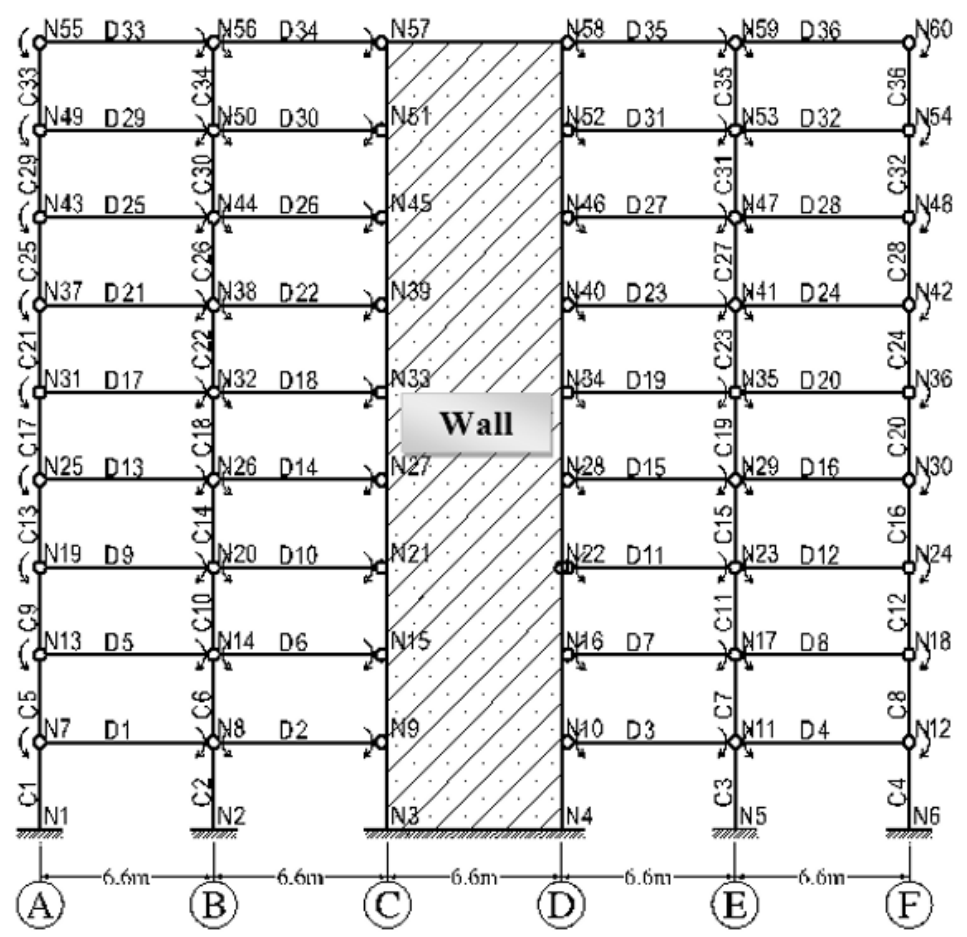

Fig 4. Node elements and semi-rigid linked frame 


\section{Results and discussion}

\subsection{Chart of displacement values on the levels}

Maximum horizontal displacement and maximum vertical displacement of the floors:
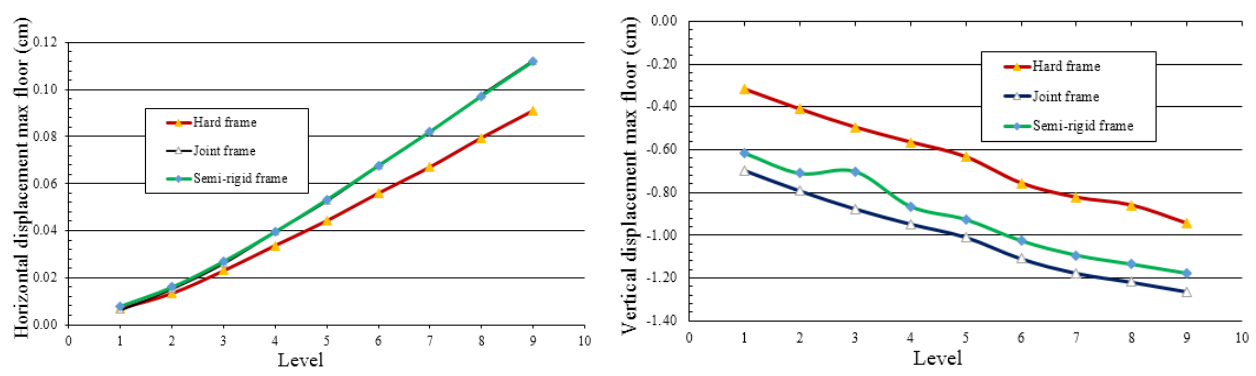

Fig 5. Vertical and horizontal displacement of the floors

\section{Comment:}

1. Vertical displacement of the floors, the semi-rigid linked frame is in the middle of the rigid linked frame and the joint linked frame. Rigid linked frame has the smallest displacements, joint linked frames have the largest displacements.

2. The horizontal displacement of the floors, joint linked frame and semi-rigid linked frame are nearly equal, rigid linked frame has the smallest displacement.

\subsection{Value chart of $M, N, Q$ on the levels}

Chart $\mathrm{M}_{\max }, \mathrm{Q}_{\max }, \mathrm{N}_{\max }$ in beams and columns:
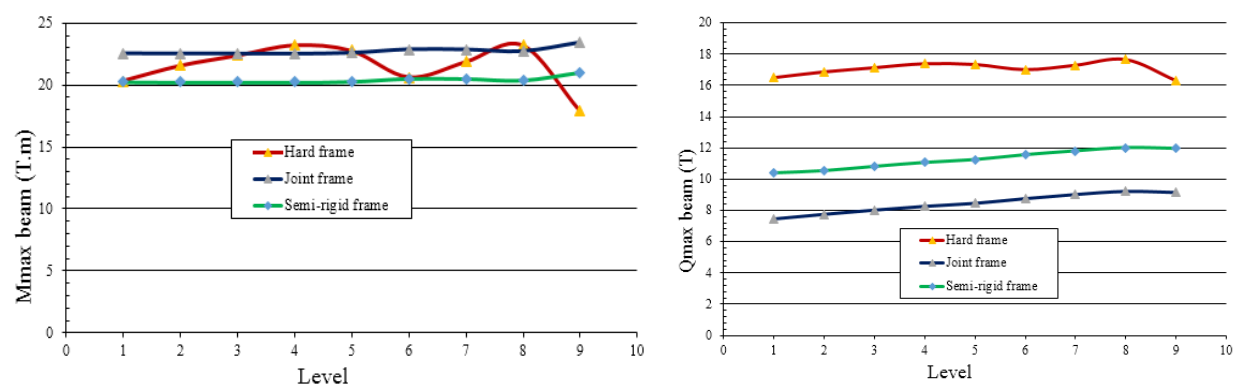

Fig 6. Chart $M_{\max }$ và $Q_{\max }$ of beams
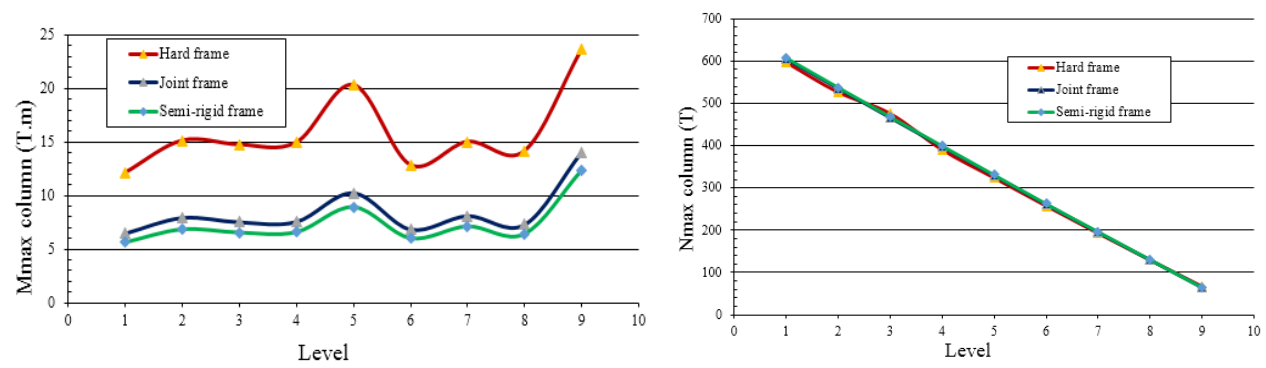

Fig 7. Chart $\mathrm{M}_{\max }$ và $\mathrm{N}_{\max }$ of columns 


\section{Comment:}

1. In beams: with $\mathrm{Q}_{\max }$, the semi-rigid linked frame is between the rigid linked frame and the joint linked frame, while $\mathrm{M}_{\max }$ the semi-rigid linked frame has the smallest value.

2. In columns: all three types of linked frame, $\mathrm{N}_{\max }$ is almost the same, and $\mathrm{M}_{\max }$ of the columns has the smallest value.

\section{Conclusions}

1. Through observation of the $\mathrm{M}_{\max }, \mathrm{N}_{\max }, \mathrm{Q}_{\max }$ chart, it is shown that with the semi-rigid linked frame, the internal force values are always intermediate of the remaining 2 diagrams, joint linked frame and rigid linked frame.

2. For $\mathrm{M}_{\max }, \mathrm{Q}_{\max }$ due to the effect of the building height, the difference in stiffness between hard wall and columns when under the influence of horizontal load, the internal distribution of elements does not follow the linear properties. Calculated as when only under the effect of staticload and liveload with simple beams. If using a rigid joint, the internal force value in the upper levels is greater than the lower levels and the curve changes the internal force value when climbing up, not following the rules of the lower levels.

3. Axial force in the links is quite similar.

4. About the price of prefabricated reinforced concrete frame will reduce $40 \%$ of the cost (materials) compared to the reinforced concrete frames poured in place. This is the advantage of prefabricated reinforced concrete frame.

\section{References}

1. A. U. Öztürk, M. Seçer, Mathю Comp. Appl., 10(1), 35-44 (2005)

2. S. C. Patodi, J. M. Chauhan, Nat. Conf. Rec. Tr. Eng. Tech., (2011)

3. V. D. Kapgate, K. N. Kadam, R. K. Rai, JCEET, 2(11), 89-94 (2015)

4. A. Csébfalvi, Opt. Des. Fra. Struct.(2007)

5. M. S. Filho; M. J. R. Guimarães; C. L. Sahlit; J. L. V. Brito, J. Braz. Soc. Mech. Sci. and Eng., (2004)

6. A. Kaveh, H.A. Rahimi Bondarabady and L. Shahryari, Int. J. Ci. Eng., 4(3), 157-175 (2006)

7. A. Daniūnas, K. Urbonas, JCEM, 237-241 (2010)

8. P. Deng, Y. Ma, 5th Intern. Conf. Adv. Eng. Mater. Tech., 851-854 (2015)

9. G. S. Nandeesha, Kashinath B R, IRJET, 4(11), 1441-1444 (2017)

10. N. Sanjaykumar, N. L. Sonune, S. S. Kalyani, IJARIIE, 3(4) (2017)

11. N. Impollonia, J Steel Struct Const, (2017)

12. L. T. Q. Khai, T. M. D. Do, IJITEE, 8(4S2) (2019)

13. L. T. Q. Khai, T. M. D. Do, IJITEE, 8(6C2) (2019)

14. L. T. Q. Khai, T. M. D. Do, IJEAT, 8(5) (2019)

15. T. M. D. Do, L. T. Q. Khai, IJITEE, 8(6C2) (2019)

16. T. M. D. Do, L. T. Q. Khai, IJEAT, 8(5) (2019) 